\title{
Effects of some anesthetic agents on skin microcirculation evaluated by laser Doppler perfusion imaging in mice
}

Sara Gargiulo ${ }^{1,2,3^{*}+}$, Matteo Gramanzini ${ }^{1,2,3+}$, Raffaele Liuzzi ${ }^{1,2}$, Adelaide Greco ${ }^{1,2,3}$, Arturo Brunetti ${ }^{1,2,3}$ and Giancarlo Vesce ${ }^{4}$

\begin{abstract}
Background: Anesthetic agents alter microcirculation, influencing tissue oxygenation and delivery of vital substrates. Laser Doppler perfusion imaging is a widespread technique in the field of microvascular research that can evaluate noninvasively and in real time the effects of environmental conditions, physical manipulations, diseases and treatments on peripheral perfusion. This study aims to evaluate laser Doppler perfusion imaging as a means to detect changes in skin microcirculation induced by some popular anesthetic agents in a murine model. Twenty-four age- and gender-matched healthy CD1 mice were examined by laser Doppler perfusion imaging. The skin microcirculatory response was measured at the level of plantar surfaces during isoflurane anesthesia with or without subsequent dexmedetomidine or acepromazine. At the end of the procedure, dexmedetomidine was reversed by atipamezole administration.
\end{abstract}

Results: In all mice, skin blood flow under isoflurane anesthesia did not show significant differences over time $(P=0.1)$. The serial perfusion pattern and values following acepromazine or dexmedetomidine administration differed significantly $(P<0.05)$.

Conclusions: We standardized a reliable laser Doppler perfusion imaging protocol to non-invasively assess changes in skin microcirculation induced by anesthesia in mice, considering the advantages and drawbacks of this technique and its translational value.

Keywords: Microvascular perfusion, Anesthesia, Murine model, Laser Doppler perfusion imaging

\section{Background}

Microcirculation is the final link between the cardiovascular system and cellular interfaces and, ultimately, molecular processes. Many studies have investigated the effect of anesthetics on peripheral and systemic microcirculation in humans [1-5], especially their effects on microvascular perfusion, aiming to ensure adequate tissue oxygenation and nutritional supply. Mice are an ideal model to study anesthetic action due to their easy manipulation, well-established behavioral and

\footnotetext{
* Correspondence: sara.gargiulo@ibb.cnr.it

${ }^{\dagger}$ Equal contributors

'Institute of Biostructures and Bioimages of the National Council of Research, Via T. De Amicis 95, Naples 80145, Italy

2 Department of Advanced Biomedical Sciences, University of Naples Federico II, Via Pansini 5, Naples 80145, Italy

Full list of author information is available at the end of the article
}

homeostatic responses to anesthesia, and well-known genetic background. Outbred mouse strains are widely used in toxicology and pharmacology, and CD1 mice have been employed in anesthesia research [6-8] on the assumption that most characteristics of interest have a polygenic inheritance and are related to phenotypic variation in a genetically heterogeneous population $[9,10]$. Moreover, anesthesia is required for most in vivo studies using mouse microcirculatory models, and the use of diverse anesthetic agents in translational research can interfere with experimental results $[11,12]$. As an example, pentobarbital [13,14], midazolam-medetomidine [15] and isoflurane [16] have been used in preclinical studies on peripheral arterial disease to evaluate the effects of new angiogenetic therapies. Microcirculatory responses to the most popular inhalation (halothane, isoflurane) or 
injectable anesthetics (propofol-fentanyl, barbiturates and ketamine) have been investigated in rats at the level of intestinal [17], cremaster or dorsal muscle microcirculation [18-20] using invasive dorsal microcirculatory chambers or intravital microscopy. So far, few data have been reported regarding the microvascular effects of the popular laboratory-animal anesthetic agents acepromazine and dexmedetomidine. Acetylpromazine maleate is an $\alpha$ adrenergic receptor antagonist broadly used for sedation and balanced anesthesia in animals [21]. Concurrent administration of acepromazine reduces the required dose of isoflurane while potentiating peripheral vasodilation and lowering blood pressure in dogs [22]. The combination of acepromazine with ketamine and xylazine is recommended for a safe and reliable surgical anesthesia in mice, although it is associated with marked hypotension $[23,24]$. Dexmedetomidine hydrochloride is a selective $\alpha_{2}$-adrenoceptor agonist with preferential affinity for $\alpha_{2} \mathrm{~A}$ and $\alpha_{2} \mathrm{~B}$ receptors [21]. Perioperative administration of dexmedetomidine hydrochloride reduces the required doses of isoflurane, thiopental and propofol in humans and animals, and it reduces the activation of the sympathetic nervous system during surgery, preventing harmful hemodynamic events such as acute kidney injury [25]. Reliable techniques for measuring perfusion in accessible tissues such as skin may have significant potential to improve our understanding of microvasculature regulation under anesthesia. Laser Doppler perfusion imaging (LDPI) is a noninvasive technique allowing real-time quantification of skin perfusion in two-dimensional color-coded images. Enhancement of the measured area provides a better evaluation of blood flow heterogeneity, allowing for the identification of subtle changes in skin perfusion induced by anesthesia and indicating circulatory status in other areas [26,27]. Although LDPI offers a simple and accurate estimate of peripheral perfusion, a standard method for the study of microcirculatory changes related to anesthesia in mice is lacking. In the present study, we reviewed several biological variables, such as gender, environmental variables and operational variables, such as body temperature, skin district and recording conditions, to develop a LDPI protocol to evaluate the effects of some anesthetic agents on microcirculation in mice. Our LDPI protocol is a potentially valuable research tool to detect in vivo real-time microcirculatory changes in preclinical experiments in mice.

\section{Results}

Standardized protocol for animal positioning and LDPI image post-processing and measurement are described in Figure 1. Sequential perfusion units (PU, volts) values for each group are reported in Table 1 as median, minimum and maximum values. No significant differences were seen between males' and females' peripheral blood

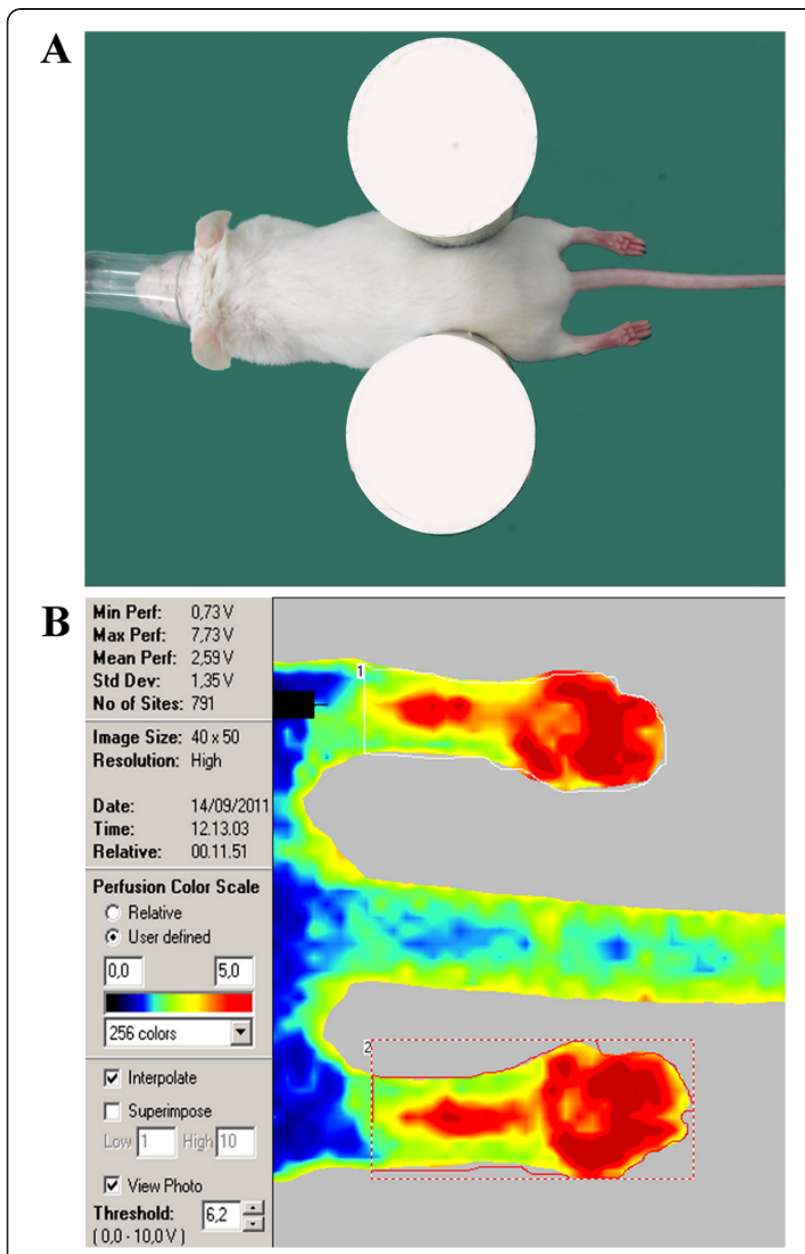

Figure 1 LDPI scan technique. (A) Animal positioning in sternal recumbency on a light-absorbing pad, with the hind plantar surfaces symmetrical and perpendicular to the laser beam. (B) LDPI image post-processing and measurement standardized protocol: the mean intensity of the Doppler signal was registered in $\mathrm{ROI}$ encompassing the hind paws and expressed as numerical value normalized for their area (perfusion color scale $0-5$ volts).

flow $(\mathrm{PBF})$ at any time point $(\mathrm{P}>0.05)$. The effects of different anesthetics on peripheral perfusion for each group are presented in Figure 2. In all mice, mean perfusion under isoflurane anesthesia showed an increasing trend at 10 and 20 minutes after maintenance (4.25 to 4.55 volts), reaching a steady perfusion value without significant differences among groups and in later times $(P=0.1)$. In contrast, the mean LDPI values following acepromazine (group 1) and dexmedetomidine administration (group 2) differed significantly. Between 10 and 20 minutes after acepromazine administration, a significant perfusion increase $(\mathrm{P}=0.005)$ was observed, from 4.55 to 4.85 volts. Dexmedetomidine administration produced a clear biphasic effect, leading to a significantly reduced $(\mathrm{P}=0.0001)$ blood perfusion $(2.47$ volts $)$ after 5 minutes, followed by an increase to 4.32 volts $(P=0.008)$ 
Table 1 Microvascular perfusion values

\begin{tabular}{|c|c|c|c|c|c|c|}
\hline \multirow[t]{2}{*}{ Groups } & \multicolumn{6}{|c|}{ Measurement time } \\
\hline & $10 \mathrm{~min}$ & $20 \mathrm{~min}$ & $25 \mathrm{~min}$ & $30 \mathrm{~min}$ & $35 \mathrm{~min}$ & $40 \mathrm{~min}$ \\
\hline 1 & $4.37 / 3.73-4.90$ & $4.57 / 3.67-5.52$ & & $4.53 / 3.98-5.53$ & & $4.84 / 4.29-5.76$ \\
\hline 2 & $4.32 / 3.69-4.75$ & $4.52 / 3.62-5.33$ & $2.37 / 2.02-3.13$ & & $4.32 / 3.73-4.81$ & $4.41 / 3.72-4.72$ \\
\hline 3 & $4.34 / 3.71-4.83$ & $4.52 / 3.66-5.50$ & & $4.57 / 3.85-5.78$ & & \\
\hline
\end{tabular}

Mouse peripheral PU (volts) in the isoflurane + acepromazine (1), isoflurane + dexmedetomidine (2) and isoflurane-alone (3) experimental groups at significative time points (median/min-max).

after 15 minutes. The latter perfusion value, close to that under isoflurane anesthesia $(P=0.6)$, was quite retained (4.34 volts) even following dexmedetomidine reversal by atipamezole (the antidote to the $\alpha_{2}$-receptor agonist) $(\mathrm{P}=0.9)$. No significant peripheral perfusion changes were observed in control mice after up to 30 minutes (4.57 volts) of $1.5 \%$ isoflurane anesthesia $(\mathrm{P}=0.11)$.

\section{Discussion}

Anesthetics modulate microcirculation mainly via autonomic sympathetic and parasympathetic nerves on vascular smooth muscle. Phenothiazine tranquilizers as well as $\alpha_{2}$-agonists exert their hemodynamic effects mainly by interacting with $\alpha$-adrenergic-receptors. Phenothiazines cause vasodilation predominantly by blocking $\alpha_{1}$ receptors but are also dopamine receptor antagonists [28]. While $\mathrm{D}_{1}$-like dopamine receptors induce relaxation of resistance arteries $[29,30] \mathrm{D}_{2}$-like dopamine receptors are typically present on postganglionic sympathetic neurons, where their excitation leads to a reduction of the neural release of norepinephrine, inducing a passive fall in vascular resistance and heart rate [31]. Dexmedetomidine is a selective $\alpha_{2}$-adrenoceptor agonist that shows a dosedependent, preferential affinity for $\alpha_{2} \mathrm{~A}$ and $\alpha_{2} \mathrm{~B}$ receptors [21], evoking a biphasic blood pressure response: a short hypertensive phase mediated by the $\alpha_{2} B$ receptors, followed by hypotension mediated by the $\alpha_{2} \mathrm{~A}$ receptors $[32,33]$. The peripheral hemodynamic effects of phenothiazines and of $\alpha_{2}$-agonists thus differ: while acepromazine causes significant hypotension in isoflurane-anesthetized

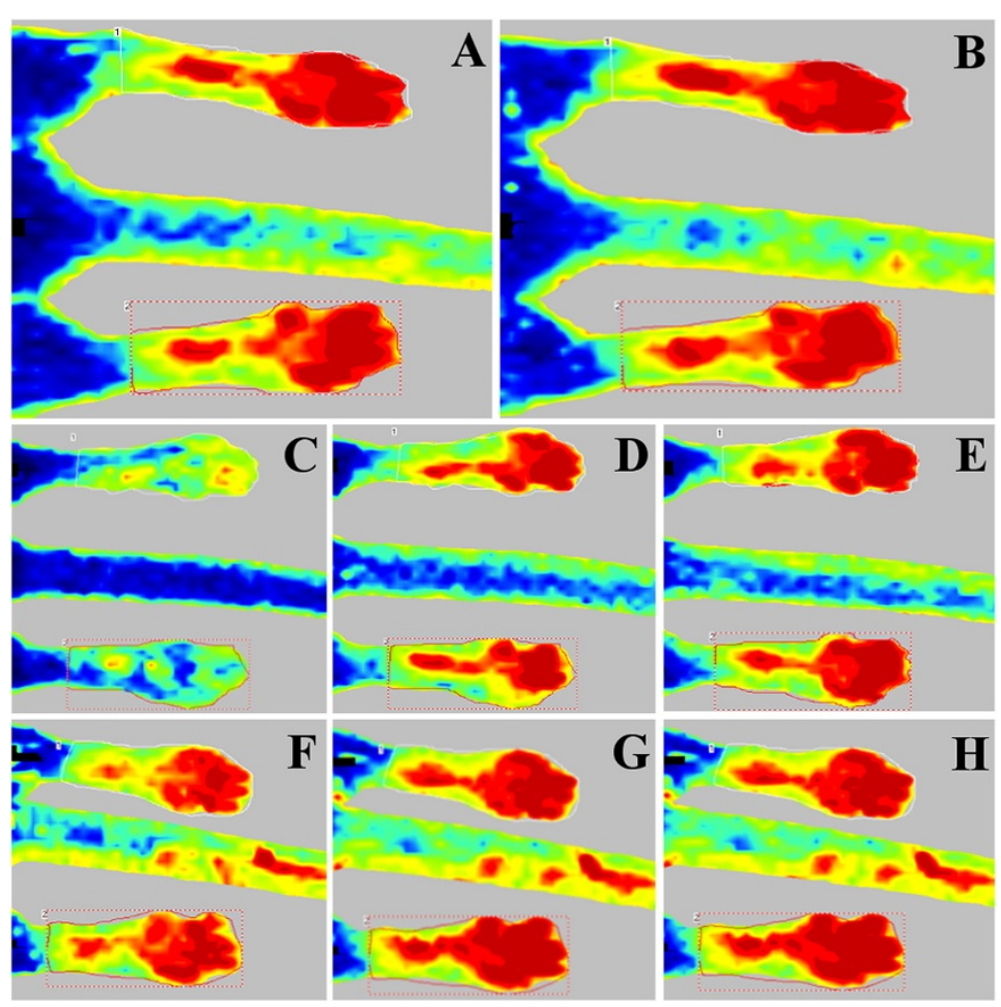

Figure 2 Representative LDPI images. Peripheral perfusion patterns in mice over time after administration of 3 anesthetic protocols. Time points with significant differences $(P<0.05$ ) are reported. Group 1 (top row) 10 (A) and 20 minutes after acepromazine injection (B); group 2 (middle row) 5 (C) and 15 minutes after dexmedetomidine injection (D) and 5 minutes after atipamezole administration (E); control group (lower row) 10 (F), 20 (G) and 30 minutes after isoflurane maintenance (H) (perfusion color scale 0-5 volts as reported in Figure 1). 
animals [34], dexmedetomidine [35,36] increases peripheral vascular tone, counteracting the isoflurane-induced vasodilation and reduction in arterial blood pressure [22]. LDPI permits a noninvasive, real-time measurement of microvascular blood flow using two-dimensional colorcoded images of skin perfusion. The use of laser doppler flowmetry technique to detect the sympathetic tone during general anesthesia in humans has been reported $[3,37,38]$, and translational approaches using LDPI in microvascular perfusion mouse models offer the advantages of being easy and fast [39]. Moreover, various anesthetics alter blood flow in rodents [40-43], so anesthetic regimens used in mouse microcirculatory models should be taken into account, and they should not adversely affect the vascular bed to be examined. The main finding in this study is that LDPI is able to evaluate in real time the anesthesia-induced changes in mouse peripheral microcirculation. The hemodynamic effects recorded during the different anesthetic protocols were as expected based on previous clinical and animal studies, although the analyzing techniques were different [2-5,22]. Because LDPI scans are disrupted by motion [44] and single or combined sedatives have lacked restraining effects in mice, we chose to perform our study under $1.5 \%$ isoflurane anesthesia to record reference perfusion values. Isoflurane produces only minor effects on murine hemodynamic status [6,7]. Costantinides et al. (2011) [45] reported that 1.5\% isoflurane produces stable body temperature, mean arterial pressure (MAP) and heart rate (HR) values in mice, comparable to those observed in awake animals, so they recommended it for physiological and pharmacological studies of cardiac function and to facilitate translational research in non-invasive imaging platforms. In the present study, isoflurane anesthesia yielded a reproducible and stable effect on peripheral blood perfusion over time $(\mathrm{P}=0.1)$. Acepromazine increased isoflurane plantar perfusion, as reported by Lemke et al. [22], and reduced vascular tone and arterial pressure due to its $\alpha$-blocking action. After dexmedetomidine administration, a rapid and intense decrease in plantar perfusion was followed by a longer phase of increased perfusion, in agreement with the typical biphasic hemodynamic effect of this class of sedatives. In all of the mice, the increased perfusion recorded 15 minutes after dexmedetomidine administration did not surpass the perfusion brought about by isoflurane $(P=0.6)$, and it was noticeably lower than the perfusion recorded following acepromazine administration $(\mathrm{P}=0.01)$, which did not increase significantly even after atipamezole injection $(\mathrm{P}=0.9)$. Special care was taken to avoid methodological bias. To date, the skin has been used as a model of microcirculation to investigate vascular mechanisms in cardiovascular [46-48] or kidney diseases [49] and diabetes [50,51]. Autonomic innervation of microvessels in the region of interest [3,28,52-54], somatic stimulation of cutaneous arterial sympathetic nerve activity [55], positioning and body temperature [56] are all crucial factors affecting skin blood flow measured by LDPI. Glabrous skin areas are highly innervated by noradrenergic sympathetic vasoconstrictor nerves $[3,28]$, which are regulated by $\alpha$-adrenoceptors [57] in several species [52-54]. For these reasons, we chose plantar region to investigate blood flow changes brought about by anesthetic drugs, also avoiding hair clipping, which might affect cutaneous arterial sympathetic nerve activity and alter LDPI measurements [55]. In our setting, precise hind plantar surface positioning was achieved to keep the site of interest highly symmetrical and precisely perpendicular to the laser beam (Figure 1) [58-60]. Moreover, body temperature was monitored by a rectal probe and adjusted between $35.5-36.5^{\circ} \mathrm{C}$ by an infrared lamp. Our experiments were performed in a temperature-controlled room [29], and we started LDPI recordings after each animal had acclimatized. The effects of sex hormones on vascular tone continue to be a matter of debate $[61,62]$. Stucker et al. (2001) [63] reported in an LDPI study only a tendency toward higher perfusion values in men than in women, stating that moderate gender differences in skin perfusion between study groups should be tolerated. Similarly, Kunkel et al. (2007) [64] found that foot skin perfusion in normal human subjects was independent of gender. In our experience, no significant differences between males and females were found in the peripheral blood flow in either control or treated animals. In accordance with the manufacturers' technical instructions, the room lighting should be kept to a minimum brightness. We set our lighting discrimination between background and the site of measurement to the default threshold level of 6.2 volts, adjusting the backscattered laser light intensity in the range of 7-9 volts, obtaining an optimum quality of data. To compare perfusion in different images, a user-defined color scale was adopted during the acquisition process, ranging from 0 to 5 volts (perfusion output value of 0 volts was calibrated to $0 \%$ perfusion, whereas 5 volts was calibrated to $100 \%)$. The average perfusion in each region of interest (ROI) was normalized to the wall plantar surface area to reduce bias related to unavoidable anatomical and position variance. To further minimize any data divergence, the hind paw perfusion value for each animal at each time point was calculated as the average value of both hind paw ROIs.

\section{Conclusions}

LDPI is able to evaluate noninvasively and in real time the skin microcirculation changes induced by general anesthesia in mouse models. LDPI could be useful for studying the effects of anesthetics on peripheral microcirculation and to avoid the inconsistent use of anesthetic agents in cardiovascular translational research. Standardization of 
an appropriate LDPI procedure is needed in preclinical studies to avoid bias in experimental results.

\section{Methods}

\section{Ethical permission}

This study was approved by the animal welfare regulation committee (CESA) of the University "Federico II" of Naples and by the Italian Ministry of Health. It complied with the Guide for the Care and Use of Laboratory Animals published by the US National Institutes of Health (NIH Publication No. 85-23, revised 1996).

\section{Study subjects and design}

Twenty-four CD1 mice (15 females and 9 males), 8 to 10 weeks old, were randomly assigned to one of three experimental groups (5 females and 3 males) and sequentially examined in identical ambient conditions. Skin perfusion was recorded by LDPI under isoflurane anesthesia combined or not with acepromazine or dexmedetomidine, as well as after the administration of atipamezole to antagonize dexmedetomidine's effects.

\section{Experimental protocol}

Animals were acclimated for $15 \mathrm{~min}$ at a room temperature of $27 \pm 3^{\circ} \mathrm{C}$ before anesthetic induction. During LDPI recording, the ambient lighting was kept at a minimum. Body temperature was monitored by a rectal temperature probe (Harvard Apparatus ${ }^{\circ}$, MLT1404) and closely adjusted to $35.5 \pm 0.5^{\circ} \mathrm{C}$ by an infrared lamp kept $60 \mathrm{~cm}$ away from the body surface. On the basis of a critical revision of the existing literature, peripheral perfusion was measured at the level of the hairless, highly sympathetic innervated plantar surfaces $[3,28]$. Animals were placed in sternal recumbency on the light-absorbing pad provided by the apparatus company, positioning the hind plantar surfaces symmetrically and perpendicularly to the laser beam (Figure 1). Isoflurane induction and maintenance were identical for all mice: each animal was weighed on a precision scale and transferred from a holding cage to a small rodent anesthetic chamber (isoflurane $4 \%$ in $2 \mathrm{~L} / \mathrm{min}$ oxygen) (ISOFLURANE-VET ${ }^{\circ}$, MERIAL ITALIA S.p.A. ${ }^{\circ}$. When deeply anesthetized, animals were placed in sternal recumbency on the recording bed and fitted with a facial mask delivering isoflurane 1.5\% in $1 \mathrm{~L} / \mathrm{min}$ oxygen. LDPI scans were recorded 10 and 20 minutes after isoflurane maintenance. Subsequent group treatments were carried out according to the schedule below, with precise time intervals between the LDPI recordings based on the pharmacodynamics of the different anesthetic agents:

Group 1 (8 subjects): Acepromazine (PREQUILLAN ${ }^{\circ}$, FATRO S.p.A. $\left.{ }^{\circ}\right) 5 \mathrm{mg} / \mathrm{kg}(=0.99 \mathrm{mg} / \mathrm{kcal})$ was administered intraperitoneally (IP), followed by two LDPI scans at an interval of ten minutes.
Group 2 (8 subjects): Dexmedetomidine (DEXDOMITOR ${ }^{\circ}$, Pfizer Italia $\left.\mathrm{Srl}^{\circ}\right) 1 \mathrm{mg} / \mathrm{kg}(=0.19 \mathrm{mg} / \mathrm{kcal})$ was administered IP, followed by two LDPI scans after 5 and $15 \mathrm{mi}$ nutes. Finally, dexmedetomidine was reversed by injecting the $\alpha_{2}$-adrenoceptor antagonist atipamezole (ATIPAM, Fatro $\left.{ }^{\circ}\right) 2.5 \mathrm{mg} / \mathrm{kg}(=0.49 \mathrm{mg} / \mathrm{kcal})$ IP, and a further LDPI scan was performed after 5 minutes.

Group 3 "control" (8 subjects): an additional LDPI scan was recorded 30 minutes after isoflurane maintenance.

\section{Laser Doppler imaging system}

The Periscan ${ }^{\circ}$ apparatus displayed the blood perfusion signal both as a numerical PU (volts) and as a colorcoded image ranging from dark blue (low perfusion) to bright red (high perfusion). The settings used in the present study were laser beam power $=1 \mathrm{mV}$; wavelength $=670 \mathrm{~nm}$; pixel size $=0.25 \times 0.25 \mathrm{~mm}^{2}$; scanner head distance $=15 \mathrm{~cm}$; scanning area $=3 \times 2 \mathrm{~cm}^{2}$; scanning time $=2$ minutes.

\section{Data processing}

The mean intensity of the Doppler signal was quantified using proprietary software in a fixed ROI, encompassing the corresponding hind paw regions, normalized for the areas of the hind paws and expressed as numerical values (volts) to reduce the bias related to unavoidable anatomical and position variance. To further minimize any data divergence, the hind paw perfusion value for each animal at each time point was calculated as the average value of both hind paw ROIs.

\section{Data analysis}

Statistical analysis was carried out using the software SPSS 18.0.2. (SPSS, Chicago, IL). To compare intergroup differences, one way Friedman ANOVA was used. A post hoc analysis with Dunn's test was performed when appropriate. A linear generalized model (LGM) for repeated measurements (two-way ANOVA) was used to assess perfusion patterns at different times within groups. A P value $<0.05$ was considered statistically significant.

\section{Abbreviations \\ HR: Heart rate; IP: Intraperitoneally; LDPI: Laser Doppler perfusion imaging; MAP: Mean arterial pressure; PU: Perfusion units; ROI: Region of interest.}

\section{Competing interests}

The authors declare that they have no competing interests.

\section{Authors' contributions}

$\mathrm{SG}, \mathrm{MG}, \mathrm{AB}$ and $\mathrm{GV}$ conceived and designed this study, as well as contribuited to data interpretation and drafted the manuscript. SG, MG, and GV carried out the experiments. AG took part in the data collection. SG and MG analysed and arranged data for statistical analysis. RL performed the statistical analyses. SG and MG made equal contribution to this study and should be considered first authors. All authors read and approved the final manuscript. 


\section{Author details}

'Institute of Biostructures and Bioimages of the National Council of Research, Via T. De Amicis 95, Naples 80145, Italy. ${ }^{2}$ Department of Advanced Biomedical Sciences, University of Naples Federico II, Via Pansini 5, Naples 80145, Italy. ${ }^{3}$ CEINGE scarl, Via G. Salvatore 486, Naples 80145 , Italy. ${ }^{4}$ Department of Veterinary Medicine and Animal Productions, University of Naples Federico II, Via Delpino 1, Naples 80137, Italy.

Received: 9 September 2013 Accepted: 2 December 2013

Published: 17 December 2013

\section{References}

1. Longnecker DE: Effects of general anesthetics on the microcirculation Microcirc Endothelium Lymphatics 1984, 2:129-150.

2. Lamblin V, Favory R, Boulo M, Mathieu D: Microcirculatory alterations induced by sedation in intensive care patients: effects of midazolam alone and in association with sufentanil. Crit Care 2006, 6:176-185.

3. Landsverk SA, Kvandal P, Bernjak A, Stefanovska A, Kirkeboe KA: The effects of general anesthesia on human skin microcirculation evaluated by wavelet transform. Anesth Analg 2007, 4:1012-1019.

4. Turek Z, Sykora R, Matejovic M, Cerni V: Anesthesia and microcirculation. Semin Cardiothorac Vasc Anesth 2009, 4:249-258.

5. Klamt JC, de Andrade Vincente WV, Vicente Garcia L: Effects of dexmedetomidine-fentanyl infusion on blood pressure and heart rate during cardiac surgery in children. Anesthesiol Res Pract 2010. doi:10.1155/ 2010/869049.

6. Zuurbier CJ, Emons VM, Ince C: Hemodynamics of anesthetized ventilated mouse models: aspects of anesthetics, fluid support and strain. Am J Physiol 2002, 6:2099-2105.

7. Janssen BJA, De Celle T, Debets JJM, Brouns AE, Callahan MF, Smith TL: Effects of anesthetics on systemic hemodynamics in mice. Am J Physiol Heart Circ Physiol 2004, 4:1618-1624.

8. Wang Q, Zheng Y, Lu J, Chen L, Wang GN, Zhou JX: Isoflurane potency in mice from the first and second parity. JALAAS 2009, 6:714-717.

9. Yalcin B, Nicod J, Bhomra A, Davidson S, Cleak J, Farinelli L, Osteras M, Whitley A, Yuan W, Gan X, Goodson M, Klenerman P, Satpathy A, Mathis D, Benoist C, Adams DJ, Mott R, Flint J: Commercially available outbred mice for genome-wide association studies. PLoS Genet 2010, 9. doi:10.1371/ journal.pgen.1001085.

10. Aldinger KA, Sokoloff G, Rosenberg DM, Palmer AA, Millen KJ: Genetic variation and population substructure in outbred CD-1 mice: implications for genome-wide association studies. PLoS One 2009, 3:e4729. doi:10.1371/ journal.pone.0004729.

11. Gargiulo S, Greco A, Gramanzini M, Esposito S, Affuso A, Brunetti A, Vesce G: Mice anesthesia, analgesia, and care, part I: anesthetic considerations in preclinical research. ILAR J 2012, 53:55-69.

12. Gargiulo S, Greco A, Gramanzini M, Esposito S, Affuso A, Brunetti A, Vesce G: Mice anesthesia, analgesia, and care, part II: special considerations for preclinical imaging studies. ILAR J 2012, 53:70-81.

13. Couffinhal T, Silver M, Zheng LP, Kearney M, Witzenbichler B, Isner JM: Mouse model of angiogenesis. Am J Pathol 1998, 6:1667-1679.

14. Li Y, Zhang D, Zhang Y, He G, Zhang F: Augmentation of neovascularization in murine hindlimb ischemia by combined therapy with simvastatin and bone marrow-derived mesenchymal stem cells transplantation. J Biomed Sci 2010, 17. doi: 10.1186/1423-0127-17-75.

15. Hellingman AA, Bastiaansen AJNM, de Vries MR, Seghers L, Lijkwan MA, Löwik CW, Hamming JF, Quax PHA: Variations in surgical procedures for hind limb ischaemia mouse models result in differences in collateral formation. Eur J Vasc Endovasc Surg 2010, 6:796-803.

16. Silvestre JS, Mallat Z, Duriez M, Tamarat R, Bureau MF, Scherman D, Duverger N, Branellec D, Tedgui A, Levy Bl: Antiangiogenic effect of interleukin-10 in ischemia-induced angiogenesis in mice hindlimb. Circ Res 2000, 6:448-452

17. Lehmann $\mathrm{CH}$, Feyerherd F, Feyerherd $T H$, Fogliata $M$, Grundling $M$, Usichenko TI, Meisser K, Wendt M, Pavlovic D: Ketamine does not affect intestinal microcirculation in pentobarbital-anaesthetized rats during experimental endotoxaemia. Lab Anim 2007, 1:55-62.

18. Kusza K, Siemionow M, Nalbantoglu U, Hayes J, Wong KC: Microcirculatory response to halothane and isoflurane anesthesia. Ann Plast Surg 1999, 1:57-66.
19. Brookes ZLS, Brown NJ, Reilly CS: Intravenous anaesthesia and the rat microcirculation: microcirculatory chamber. Brit J Anaesth 2000, 6:901-903

20. Brookes ZL, Brown NJ, Reilly CS: Response of the rat cremaster microcirculation to hemorrhage in vivo: differential effects of intravenous anesthetic agents. Shock 2002, 6:542-548.

21. Posner $L P$, Burns $P$ : Sedative agents: tranquilizers $\alpha$-2agonists and related agents. In Veterinary pharmacology and therapeutics. Edited by Riviere JE, Papich MG. Ames, lowa: Wiley Blackwell; 2009:337-380.

22. Lemke KA: Perioperative use of selective $a-2$ agonists and antagonists in small animals. Can Vet J 2004, 6:475-480.

23. Arras M, Autenried P, Rettich A, Spaeni D, Tülicke T: Optimization of intraperitoneal injection anesthesia in mice: drugs, dosages, adverse effects and anesthesia depth. Comp Med 2001, 5:443-456.

24. Buitrago S, Martin TE, Tetens-Woodring J, Belicha-Villaneueva A, Wilding GE: Safety and efficacy of various combinations of injectable anesthetics in Balb/C mice. JAALAS 2008, 1:11-17.

25. Leino K, Hynynen M, Jalonen J, Salmenperä M, Scheinin H, Aanta R: Renal effects of dexmedetomidine during coronary artery bypass surgery: a randomized control-controlled study. BMC Anesthesiol 2011, 23:9-19.

26. Holowatz LA, Thompson-Torgerson CS, Kenney WL: The human cutaneous circulation as a model of generalized microvascular function. $J$ Appl Physiol 2008, 1:370-372.

27. Samuelsson A: Effects of burns and vasoactive drugs on human skin. In Clinical and Experimental studies using microdialysis. Linköping, Sweden: Linköping University Medical Dissertations No. 1195 LIU-tryck; 2010.

28. Pascoe PJ, Taylor MA: Effects of dopamine antagonists on alfentanilinduced locomotor activity in horses. Vet Anaesth Analg 2003, 3:165-171.

29. Zeng C, Eisner GM, Felder RA, Jose PA: Dopamine receptor and hypertension. Curr Med Chem Cardiovasc Hematol Agents 2005, 1:69-77.

30. Jose PA, Eisner GM, Felder RA: Role of dopamine receptors in the kidney in the regulation of blood pressure. Curr Opin Nephrol Hypertens 2002, $1: 87-92$.

31. Cavero I, Massingham R, Borg FL: Peripheral dopamine receptors, potential targets for a new class of antihypertensive agents: Part I: subclassification and functional description. Life Sci 1982, 10:939-948.

32. Kaur M, Singh PM: Current role of dexmedetomidine in clinical anesthesia and intensive care. Anesth Essays Res 2011, 2:128-133.

33. Papadakos PJ, Compolo F: Sedation in the ICU: shifts and strategies. Anesthesiology News 2011:80-91.

34. Bostrom I, Nyman G, Kampa N, Haggstrom J, Lord P: Effects of acepromazine on renal function in anesthetized dogs. Am J Vet Res 2003, 5:590-598.

35. Cullen LK: Medetomidine sedation in dogs and cats: a review of its pharmacology, antagonism and dose. Br Vet J 1996, 5:519-535.

36. Baker NJ, Schofield JC, Caswell MD: Effects of early atipamezole reversal of medetomidine-ketamine anesthesia in mice. J Am Assoc Lab Anim Sci 2011, 6:916-920.

37. Humeau A, Steenbergen W, Nilsson H, Strümberg T: Laser doppler perfusion monitoring and imaging: novel approaches. Med Biol Eng Comput 2007, 5:421-435.

38. Takashi M, Ping Z, Takahiko K, Yoshimi I, Akitoshi O, Atsushi Y, Ikuto Y: Laser doppler skin blood flow and sympathetic nervous responses to surgical incision during halothane and isoflurane anesthesia. Anesth Analg 1997, 2:291-298.

39. Al-Mubarak HA, Alamri TM, Aljabab SA, Atteya M, Quan A, Teoh H, Shukla PC, Verma S, Aldahmash A, Aljabri B, Napoli C, Al-Omran M: Effects on duration of post-operative ischemia and patterns of blood flow recovery in different conditions of mouse hind limb ischemia. Vasc Cell 2011, 3. doi:10.1186/2045-824X-3-14

40. Dalkara T, Irikura K, Huang Z, Panahian N, Moskowitz MA: Cerebrovascular responses under controlled and monitored physiological conditions in the anesthetized mouse. J Cereb Blood Flow Metab 1995, 4:631-638.

41. Koorn R, Kahn RA, Brannan TS, Martinez-Tica J, Weinberger J, Reich DL: Effect of isoflurane and halothane on in vivo ischemia-induced dopamine release in the corpus striatum of the rat: a study using cerebral microdialysis. Anesthesiology 1993, 1:827-835.

42. Lindauer U, Villringer A, Dirnagl U: Characterization of CBF response to somatosensory stimulation: model and influence of anesthetics. Am J Physiol 1993, 4:1223-1228.

43. Greco A, Ragucci M, Liuzzi R, Gargiulo S, Gramanzini M, Coda ARD, Albanese S, Mancini M, Salvatore M, Brunetti A: Reproducibility and standardization 
of laser doppler Imaging technique for the evaluation of normal mice hindlimbs perfusion. Sensor 2012, 13:500-515.

44. Dirnagl U, Kaplan B, Jacewicz M, Pulsinelli W: Continuous measurement of cerebral cortical blood flow by laser-Doppler flowmetry in a rat stroke model. J Cereb Blood Flow Metab 1989, 5:589-596.

45. Constantinides $C$, Mean R, Janssen BJ: Effects of isoflurane anesthesia on the cardiovascular function of the C57BL/6 mouse. ILAR J 2011, 52:21-31.

46. Antonios TF, Singer DR, Markandu ND, Mortimer PS, MacGregor GA: Structural skin capillary rarefaction in essential hypertension. Hypertension 1999, 33:998-1001.

47. Feihl F, Liaudet L, Waeber B, Levy Bl: Hypertension: a disease of the microcirculation? Hypertension 2006, 6:1012-1017.

48. Levy BI, Schiffrin EL, Mourad JJ, Agostani D, Vicaut E, Safar ME, StruijkerBoudier HA: Impaired tissue perfusion: a pathology common to hypertension, obesity, and diabetes mellitus. Circulation 2008, 9:968-976.

49. Kruger A, Stewart J, Sahityani R, O'Riordan E, Thompson C, Adler S, Garrick R, Vallance P, Goligorsky MS: Laser Doppler flowmetry detection of endothelial dysfunction in end-stage renal disease patients: correlation with cardiovascular risk. Kidney Int 2006, 1:157-164.

50. Chang CH, Tsai RK, Wu WC, Kuo SL, Yu HS: Use of dynamic capillaroscopy for studying cutaneous microcirculation in patients with diabetes mellitus. Microvasc Res 1997, 2:121-127.

51. Yamamoto-Suganuma R, Aso Y: Relationship between post-occlusive forearm skin reactive hyperaemia and vascular disease in patients with Type 2 diabetes - a novel index for detecting micro- and macrovascular dysfunction using laser Doppler flowmetry. Diabet Med 2009, 1:83-88.

52. Koganezawa T, Ishikawa T, Fujita Y, Yamashita T, Tajima T, Honda M, Nakayama K: Local regulation of skin blood flow during cooling involving presynaptic P2 purinoceptors in rats. Br J Pharmacol 2006, 5:579-586.

53. Honda M, Suzuki M, Nakayama K, Ishikawa T: Role of a2C-adrenoceptors in the reduction of skin blood flow induced by local cooling in mice. $\mathrm{Br} J$ Pharmacol 2007, 1:91-100.

54. Mayrovitz HN, Carta SG: Laser Doppler Imaging Assessment of skin Hyperemia indicator of trauma after adhesive strip removal. Adv Wound Care 1996, 4:38-42.

55. Horii Y, Tanida M, Shen J, Fujisaki Y, Fuyuki R, Hashimoto K, Niijima A, Nakashima T, Katsuya N: Skin application of urea-containing cream affected cutaneous arterial sympathetic nerve activity, blood flow, and water evaporation. Skin Res Technol 2011, 1:75-81.

56. Kuluz JW, Prado R, Chang J, Ginsberg MD, Schleien CL, Busto R: Selective brain cooling increases cortical cerebral blood flow in rats. Am J Physiol 1993, 3:824-827.

57. Lawrence CJ, Prinzen FW, de Lange S: The effect of dexmedetomidine on nutrient organ blood flow. Anesth Analg 1996, 6:1160-1165.

58. Belin de Chantemèle EJ, Ali MI, Mitz J, Stepp DW: Obesity induced insulin resistance causes endothelial dysfunction without reducing the vascular response to hindlimb ischemia. Basic Res Cardiol 2009, 6:707-717.

59. Anderson RR, Parrish JA: The optics of human skin. J Invest Dermatol 1981, 1:13-19.

60. Fredriksson I, Larsson M, Strömberg T: Measurement depth and volume in laser Doppler flowmetry. Microvasc Res 2009, 1:4-13.

61. Cankar K, Finderle Z, Strucl M: Role of alpha-adrenoceptors in the cutaneous postocclusive reactive hyperaemia. Pflugers Arch 2000, 5:121-122.

62. Cankar K, Finderle Z, Strucl M: The role of alpha1- and alpha2- adrenoceptors in gender differences in cutaneous LD flux response to local cooling. Microvasc Res 2004, 2:126-131.

63. Stücker M, Steinberg J, Memmel U, Avermaete A, Hoffmann K, Altmeyer P: Differences in the two-dimensionally measured laser Doppler flow at different skin localisations. Skin Pharmacol Appl Skin Physiol 2001, 1:44-51

64. Kunkel CF, Figoni SF, Baumgarten JM: Scanning laser-Doppler imaging of leg- and foot-skin perfusion in normal subjects: analysis of age, gender, site, and laser-type effects. Am J Phys Med Rehabil 2007, 4:262-271.

doi:10.1186/1746-6148-9-255

Cite this article as: Gargiulo et al.: Effects of some anesthetic agents on skin microcirculation evaluated by laser Doppler perfusion imaging in mice. BMC Veterinary Research 2013 9:255.

\section{Submit your next manuscript to BioMed Central and take full advantage of:}

- Convenient online submission

- Thorough peer review

- No space constraints or color figure charges

- Immediate publication on acceptance

- Inclusion in PubMed, CAS, Scopus and Google Scholar

- Research which is freely available for redistribution 